\title{
A multi-scale, multi-model approach for analyzing the future dynamics of European land use
}

\author{
Peter H. Verburg • Bas Eickhout • Hans van Meijl
}

Received: 15 February 2006 / Revised: 29 August 2006 / Published online: 4 August 2007 C Springer-Verlag 2007

\begin{abstract}
Europe's rural areas are expected to witness massive and rapid changes in land use due to changes in demography, global trade, technology and enlargement of the European Union. Changes in demand for agricultural products and agrarian production structure are likely to have a large impact on landscape quality and the value of natural areas. Most studies address these changes either from a macro-economic perspective focusing on changes in the agricultural sector or from a local perspective by analyzing recent changes in landscapes for small case studies. This paper describes a methodology in which a series of models has been used to link global level developments influencing land use to local level impacts. It is argued that such an approach is needed to properly address the processes at different scales that give rise to the land use dynamics in Europe. An extended version of the global economic model (GTAP) and an integrated assessment model (IMAGE) are used to calculate changes in demand for agricultural areas at the country level while a spatially explicit land use change model (CLUE-s) was used to translate these demands to land use patterns at $1 \mathrm{~km}^{2}$ resolution. The global economic model ensures an appropriate treatment of
\end{abstract}

\footnotetext{
P. H. Verburg $(\bowtie)$

Department of Environmental Sciences, Wageningen University, P. O. Box 47, 6700 AA Wageningen, The Netherlands

e-mail: peter.verburg@wur.nl

B. Eickhout

Department of Global Sustainability and Climate,

Netherlands Environmental Assessment Agency (MNP/RIVM),

P. O. Box 303, 3720 AH Bilthoven, The Netherlands

e-mail: Bas.Eickhout@mnp.nl

H. van Meijl

Agricultural Economics Research Institute (LEI), Wageningen University and Research Centre,

P. O. Box 29703, 2502 LS The Hague, The Netherlands

e-mail: hans.vanmeijl@wur.nl
} 
macro-economic, demographic and technology developments and changes in agricultural and trade policies influencing the demand and supply for land use related products while the integrated assessment model accounts for changes in productivity as result of climate change and global land allocation. The land use change simulations at a high spatial resolution make use of country specific driving factors that influence the spatial patterns of land use, accounting for the spatial variation in the biophysical and socio-economic environment. Results indicate the large impact abandonment of agricultural land and urbanization may have on future European landscapes. Such results have the potential to support discussions on the future of the rural area and identify hot-spots of landscape change that need specific consideration. The high spatial and thematic resolution of the results allows the assessment of impacts of these changes on different environmental indicators, such as carbon sequestration and biodiversity. The global assessment allows, at the same time, to account for the tradeoffs between impacts in Europe and effects outside Europe.

JEL Classification $\mathrm{C} 68 \cdot \mathrm{R} 14 \cdot \mathrm{R} 15 \cdot \mathrm{R} 52$

\section{Introduction}

European land use is subject to a multitude of changes set in motion by a variety of interacting processes (Klijn 2004). These processes act at different scales and in different domains. The most dominant processes of change include economic growth, technological change and the political changes in Europe. The ongoing enlargement of the European Union, the challenge to bridge socio-economic differences between older and newer member states and the formation of a larger internal market are likely to affect land use. The recent reforms of the Common Agricultural Policy change support from distorting market price support to less distorting income support which has an impact on agricultural production and land use (Meijl and Tongeren 2002). The Lisbon strategy that was agreed on by the European member states aims at economic restoration and a leading position of the European Union in the global economy. At the same time Europe faces large demographic changes including the stagnation or even a decline in population numbers, aging and migration from rural to urban areas (Lindh 2003). Apart from these changes within Europe itself also global level developments have large impacts on European land use. These global-scale developments include the changes in trade arrangements and the ongoing globalization of markets. Further trade liberalization as agreed in the Doha Development Agenda should contribute also to development and environment. However, the effects are heavily debated (Francois et al. 2005) but it is certain that a further liberalization will have a large impact on land use globally. Global changes in climate, impacts on the environmental and social systems and policies to reduce emissions of greenhouse gases will affect land use decisions in Europe as well (Strengers et al. 2004; Dockerty et al. 2006). Other relevant processes such as urban and infrastructure developments act more locally or regionally.

The extent of these changes and the likely impacts on environment, landscapes and rural livelihoods are largely unknown. Besides threats these changes in land use will provide opportunities for socio-cultural, economic and ecological values. As policy makers need to act in an anticipative or pro-active manner they need to be informed 
timely on what will or could happen and on what could be done to lessen risks and to stimulate promising developments (Bennett et al. 2003). Therefore, policy makers and scientists have together identified the need to explore the potential dynamics of land use change and associated impacts for the European Union (Klijn et al. 2005).

Different types of research that could potentially support policy makers in the identified challenges are available (Bennett et al. 2003). Research may aim at designing solutions for specific problems by calculating the optimal land use allocation given a set of objectives (van Ittersum et al. 2004; Loonen et al. 2006). Such studies may be used to determine optimal locations for urban development or intensive agriculture to minimize negative impacts on other land use functions. Other studies aim at the evaluation of the efficiency of policies on land use to achieve the policy intentions (ex-ante assessment) (Britz et al. 2002; Meijl and Tongeren 2002). These two types of research aim at direct support of policy decisions. Another type of studies do not aim at decision support for specific policies but, instead, aim at providing assessments that will provoke policy discussions and help to think about the future of complex systems or identify policy alternatives. A popular type of discussion support is the use of scenarios (Rotmans et al. 2000; Peterson et al. 2003; Xiang and Clarke 2003; Wester-Herber 2004). Scenarios are a means to sketch what could happen, assuming changes in preconditions that differ in nature, course, rate, duration or place. In many cases models are used to explore the consequences of these assumed changes in preconditions on the studied system. Such explorative scenarios help to delineate the margins of the possible and conceivable and are a means to explore and map uncertainties in the development of systems. A good example of a scenario study that proved to exert some shock effects on politicians and stakeholders was the study titled 'Ground for choices' (WRR 1992; Rabbinge et al. 1994), indicating that agriculture in Europe could do with an significantly smaller area if practiced at a much higher level of efficiency. Scenarios are rooted in complex, though internally consistent and explicit world views. These include certain reasonably underpinned assumptions (e.g. demographic developments) and beliefs (e.g. in the blessings of a free market). There is neither a most probable development nor a best attitude on beforehand. The role of such scenarios is to make explicit what the alternative assumptions, beliefs and attitudes are and the role of simulation models to show the various contrasting and even surprising outcomes that can confirm or deny the various expectations. That aspect, the correspondence between what should be and what will be may fuel discussions and self-reflection (Klijn et al. 2005; Westhoek et al. 2006). Characteristic for such scenario studies is the focus on medium to long-term development. Scenarios studies are popular and many studies have been conducted to assess environmental impact at the global level, e.g. the climate change related studies of the Intergovernmental Panel on Climate Change (IPCC 2000; Arnell et al. 2004), the Global Environmental Outlook (UNEP 2002) and the Millennium Ecosystem Assessment (MEA 2005). For an assessment of the developments at the European level these global studies do not provide sufficient detail and exclude European specific policies and developments. The spatial resolution of analysis is mostly limited to $50 \times 50 \mathrm{~km}$ due to the reliance on global scale models (Strengers et al. 2004). Even the recent European assessment by the Advanced Terrestrial Ecosystem Analysis and Modeling project (Rounsevell et al. 2005; Schröter et al. 2005) and the PRELUDE project (EEA 2005) do not go 
below a spatial resolution of 10 min which is not sufficient to identify changes in landscape pattern. A coarse resolution makes an assessment of impacts on issues like biodiversity and carbon stock changes difficult since most impacts are location specific. When making assessments for the medium to long-term, with the possibility to explore relatively large changes, it is needed to assess the interactions between land use change processes at different scales. Therefore, it is not possible to only focus on Europe while disregarding the rest of the global developments. Multiple interactions between the European and global scale will influence both land use inside and outside Europe. Most scenario studies do not consider this full range of scales.

In this paper we present a novel, scenario-based, modeling approach to support policy discussions as developed in the EURURALIS project. The approach is designed to address processes relevant to land use change over the full range of scales from the global level to the local, landscape level. This paper describes the overall modeling approach and a selection of the results while specific details on the individual models can be found in other publications related to this project (Eickhout et al. 2007; Meij1 et al. 2006; Verburg et al. 2006; Westhoek et al. 2006).

\section{Methods}

\subsection{Overview}

The methodology is designed to quantify a set of scenarios based on models at different scales. Figure 1 provides an overview of this procedure. The first step is the

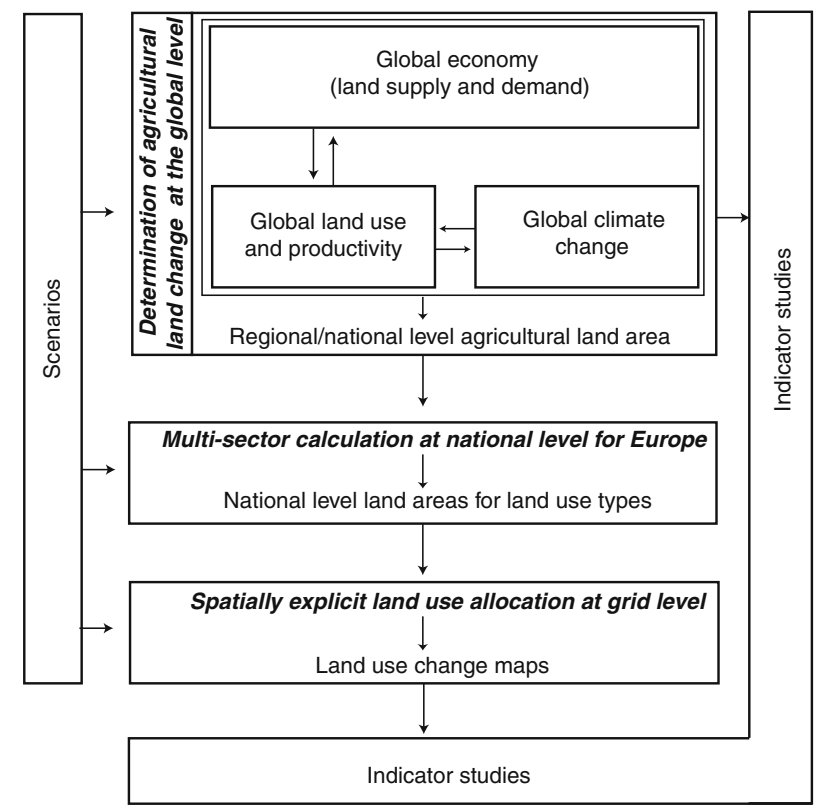

Fig. 1 Overall representation of the methodology 
elaboration of the general storylines by specifying the conditions that are needed to make an assessment of the land use dynamics. This process includes the specification of the demographic and economic trends, world trade regulations, consumer preferences and policies that (in)directly influence land use. Many of these variables, such as the expected economic and demographic developments need to be quantified since these are critical input to the models.

No single model is able to capture all key processes essential to explore land use change in Europe at the different scales relevant to make a full assessment of driving factors and impacts. Therefore, a series of different models is used to account for the structure of land use change processes. The demand for agricultural land in Europe is dependent on global developments in agricultural production, world trade agreements and changes in the economy of sectors outside agriculture. Global models are used to account for the effect of changes at the global level on European land use. At the same time, the global-level assessment also allows an evaluation of the effects of changes in Europe on other parts of the world, including an assessment of the tradeoffs of European land use change for developing countries. In this study a combination of a global economy model and a global integrated assessment model is used to capture the interaction between economy and natural resources. The world economy model calculates the economic consequences for the agricultural sector by describing features of the global food market and the dynamics that arise from the exogenous scenario assumptions. Regional food production and impacts on productivity (through intensification or extensification) as calculated by the global economy model are used as input of the integrated assessment model. This model is used to calculate the effects of land use change and climate change on yield level and simulates feed efficiency rates and a number of environmental indicators. Together, these global models result in an assessment of the agricultural land use changes at the level of individual countries inside Europe and for larger regions outside Europe (Eickhout et al. 2007; Meijl et al. 2006). At the same time these models also calculate changes in other sectors of the economy which are indirectly related to land use. This information is used in a series of simple models (Fig. 1). For the industry and services sectors the changes in sector size are translated into land requirements for these sectors (Fig. 2). For the natural and residential land use types the claims for land area are based on the demographic and policy assumptions as described in the storylines.

It is obvious that the global models are not able to make an assessment beyond the resolution of individual countries. Land use within a country is variable as result of local variations in social and biophysical conditions. Furthermore, the driving factors of landscape pattern are often region-specific as a consequence of different contextual conditions, specific variation in the socio-economic and biophysical conditions, and the influence of land use history and culture (Nassauer 1995; Naveh 2001). The actual downscaling of the national level changes to the landscape level was done by a spatially explicit land use change model at a spatial resolution of $1 \mathrm{~km}^{2}$ (Verburg et al. 2006).

Finally, based on the simulated land use changes a number of indicators were calculated to summarize the results and assess the likely impacts. Some indicators are based on the simulated land use changes itself, e.g., the 'hot-spots' of land use change, 

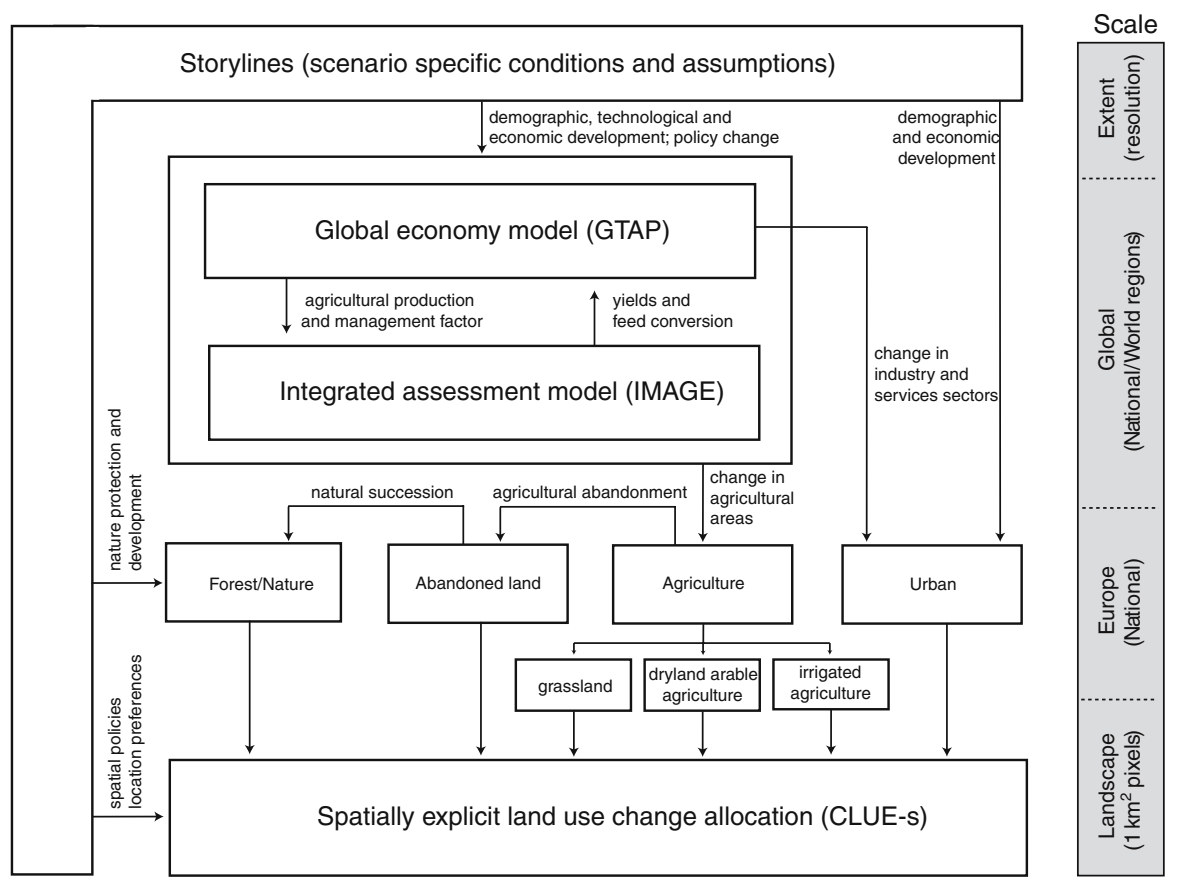

Fig. 2 Schematic representation of the modelling procedure over different scales

while others reflect the economic or environmental changes resulting from the changes in land use.

\subsection{Scenarios}

The scenarios follow the concept storylines of the IPCC Special Report on Emission Scenarios (SRES; IPCC 2000) which are structured along two axis distinguishing globalisation from regionalisation; and development pursuing narrowly defined economic objectives from more broadly defined economic, social and environmental objectives. However, the focus of these scenarios is completely outside land use, agriculture and rural development and lacks the regional disaggregating needed for this study. Therefore the scenarios were elaborated for land use issues and agricultural policies typical for Europe (Westhoek et al. 2006). This resulted in a series of four scenarios distinguished by different degrees of global (market) integration and different levels of (policy) regulation (Fig. 3). The regulation level is indicative for the ambition of governments in pursuing its goals with ambitious regulation, e.g., to obtain equity or environmental sustainability. Scenarios with a relatively low level of regulation include the Global Economy (A1) and Continental Market (A2) scenarios. The other two scenarios: Global Co-operation (B1) and Regional Communities (B2) assume a relatively high level of regulation, including specific spatial and agricultural policies. 


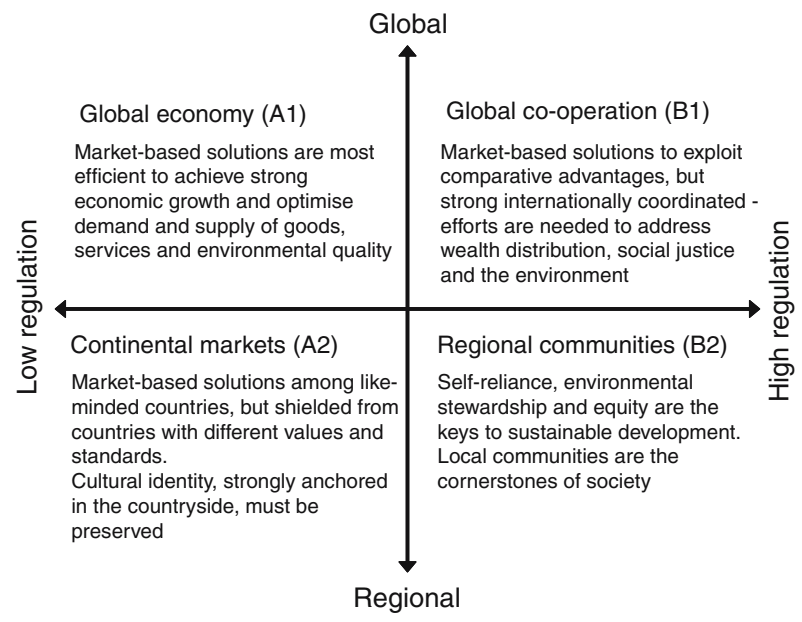

Fig. 3 Scenarios used in the EURURALIS project (Westhoek et al. 2006)

The elaboration of the scenarios also included the quantification of variables exogenous to the simulation models representing the developments assumed in the scenarios. These exogenous variables include demography, institutions, trade barriers and technology parameters. A selection of the assumptions made in the four scenarios that are explicitly accounted for in the simulations is provided in Table 1. For the quantification use was made of a number of existing scenario studies and models. In addition a number of sessions with policy makers was held to check the credibility and consistency of the story lines and model input (Klijn et al. 2005; Westhoek et al. 2006). For a complete overview of the scenario assumptions we refer to Westhoek et al. (2006).

\subsection{Models}

\subsubsection{Global-to-national scale models}

To analyze the economic and environmental consequences of economic, policy and demographic changes as well as changes in policies that influence European and global agriculture and land use a framework was developed that combines a macro-economic and an integrated assessment model (Eickhout et al. 2007; Meijl et al. 2006).

The global economy is modelled with an extended version of the Computable General Equilibrium (CGE) model (GTAP Global Trade Analysis Project; Hertel 1997), which combines the advantages of the global CGE approach, taking into consideration the impact of non-agricultural sectors on agriculture and a full treatment of factor markets, with the specific features of partial equilibrium models concerning land modeling. The standard GTAP model is characterized by an input-output structure based on regional and national input-output tables. It explicitly links industries in a value added chain from primary goods, over continuously higher stages of intermediate processing, to the final assembling of goods and services for consumption 


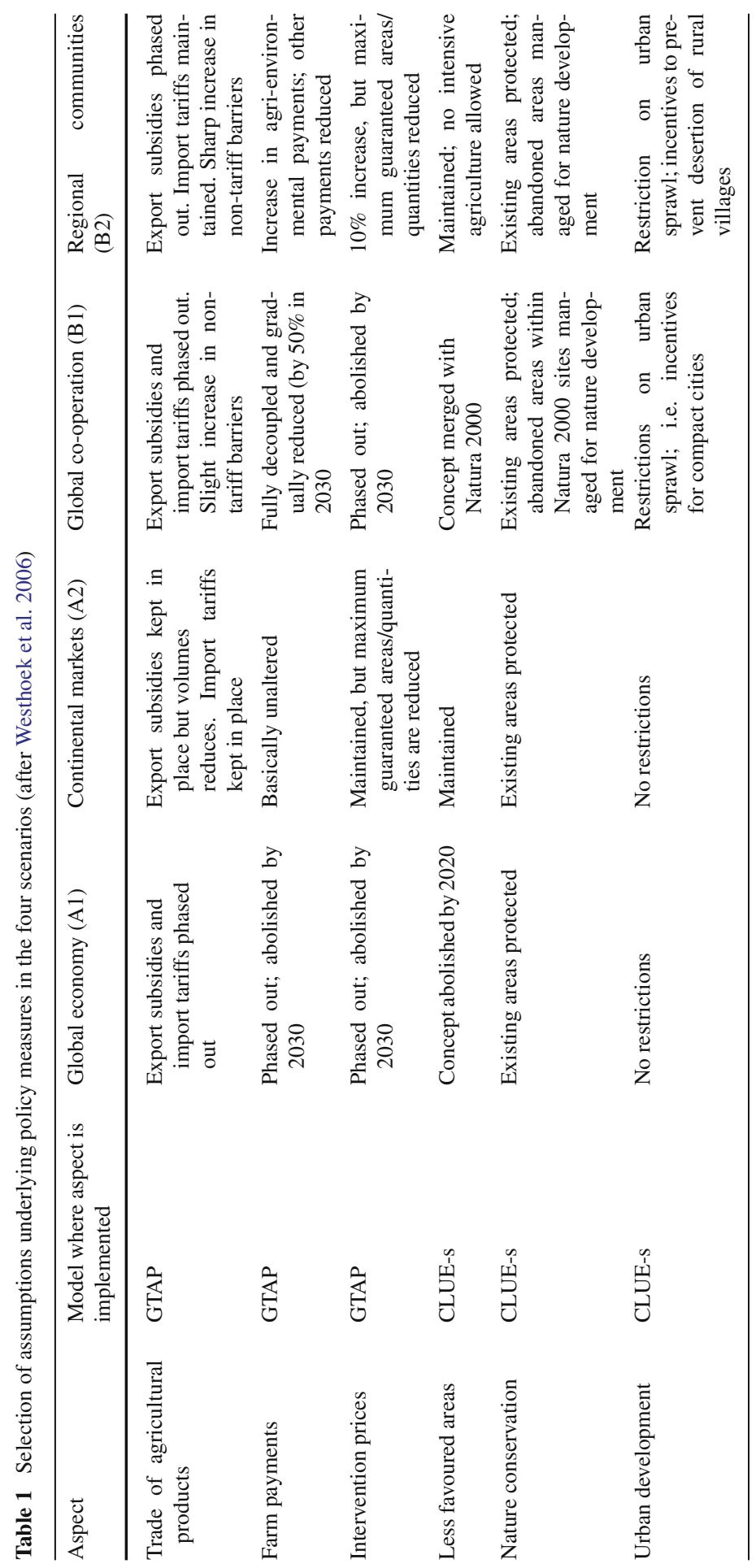


(Hertel 1997). For this analysis an extended version of the standard GTAP model was developed that improved the treatment of agricultural production and land use (Meij1 et al. 2006). Since it was assumed that the various types of land use are imperfectly substitutable, the land use allocation structure was extended by taking into account different degrees of substitutability between land use types (Huang et al. 2004). Therefore, OECD's more detailed Policy Evaluation Model structure was used (OECD 2003). It is essential that land supply, which is normally exogenous in CGE models, is made endogenous by including a land supply curve since land can move into or out of agricultural production due to several reasons, leading to exceeding or undershooting of the total available agricultural area. For example, land supply to agriculture can be adjusted as a result of idling of agricultural land, conversion of non-agricultural land to agriculture, conversion of agricultural land to urban use and agricultural land abandonment. For each country in Europe and world region outside Europe a land supply curve was estimated which specifies the relation between land supply and a rental rate. Through this land supply curve an increase in demand for agricultural purposes will lead to land conversion when land resources are abundant, while increases in demand will result in strong increases in rental rate when there are shortages of land (Meijl et al. 2006).

The most important inputs of the GTAP model are the demographic, macroeconomic and technological developments and policy assumptions. Demographic and macro-economic assumptions are expressed by population numbers and GDP, employment and capital growth. Technological growth is partly determined endogenously with relative factor prices and a yield component that is exogenously based on the scenario conditions. For the different scenarios relevant policy assumptions are implemented, including quota, changes of import tariffs and export subsidies and land subsidies for specific crops (see Table 1). More details on input data are provided by Meijl et al. (2006).

An important factor in the calculation of demand for agricultural land is the yield. In the extended GTAP model yield depends on a trend factor and on relative factor prices. The production structure used implies that substitution among production factors is possible, i.e., if the land rent increases the producer may increase the use of other production factors, such as capital and labour, which leads to improved yields.

The GTAP model calculates changes in land demand by maximizing a profit function for a representative producer for each sector of a country or region. Therefore, the model assumes homogeneity of all conditions within the country and cannot account for impacts of land use change on land productivity as result of expansion on or abandonment of marginal lands. Furthermore, the economic analysis is not capable to deal with the region-specific effects of climate change on yield (Parry et al. 2004).

To estimate the effects of land use change and climate change on yield levels and, at the same time, calculate a set of global environmental indicators, use is made of the integrated assessment model (IMAGE Integrated Model to Assess the Global Environment Alcamo et al. 1998; Strengers et al. 2004). The calculations of IMAGE start with the exogenous driving forces of population and economic growth and with the results of the global economy model, including sectoral production growth rates and changes in yield, partly on basis of endogenously determined intensification/extensification processes. The IMAGE model allocates the agricultural production on a global grid 
Table 2 Sources of yield increase of maize between 2001 and 2030 for the Global Economy (A1) scenario; determined by IMAGE

\begin{tabular}{lllllllc}
\hline & $\begin{array}{l}\text { OECD } \\
\text { Europe (\%) }\end{array}$ & $\begin{array}{l}\text { Eastern } \\
\text { Europe (\%) }\end{array}$ & $\begin{array}{l}\text { USA } \\
(\%)\end{array}$ & $\begin{array}{l}\text { South } \\
\text { America (\%) }\end{array}$ & $\begin{array}{l}\text { Western } \\
\text { Africa (\%) }\end{array}$ & $\begin{array}{l}\text { Former } \\
\text { USSR (\%) }\end{array}$ & $\begin{array}{l}\text { East } \\
\text { Asia (\%) }\end{array}$ \\
\hline $\begin{array}{l}\text { Climate change and } \\
\mathrm{CO}_{2} \text { fertilization }\end{array}$ & -14 & 2 & 2 & 1 & 2 & 3 & 2 \\
$\begin{array}{l}\text { Land use change } \\
\text { Yield increase by } \\
\text { technology }\end{array}$ & 3 & -1 & -6 & -19 & -12 & -13 & 8 \\
\hline
\end{tabular}

with a 0.5 by $0.5^{\circ}$ resolution to account for heterogeneity of land resources based on a simple allocation mechanism that basically allocates land expansion to areas with the highest potential yield and close to existing agricultural land and land abandonment on the least productive areas. The allocation mechanism of agricultural land also accounts for the distribution of population, the vicinity to water and a random factor. To account for climate change, the emissions of the energy sector need to be considered. Emissions from the energy sector are taken from Bollen et al. (2004), in which the same driving forces and scenario assumptions are used for future projections of the energy sector. The atmospheric and ocean models connected to IMAGE calculate changes in atmospheric composition by employing the emissions and by taking oceanic $\mathrm{CO}_{2}$ uptake and atmospheric chemistry into consideration. Subsequently, changes in climatic properties are computed by resolving oceanic heat transport and the changes in radiation forcing by greenhouse gases and aerosols. The impact models involve specific models for sea-level rise and land degradation risk and make use of specific features of the ecosystem and crop models to depict impacts on vegetation and crop growth (Leemans and Eickhout 2004). The climate and $\mathrm{CO}_{2}$ feedbacks are simulated dynamically, and together with the impact on yields due to land use change, they provide a modified crop yield for each country or world region considered in the GTAP model. A similar procedure is followed for feed conversion factors for the livestock sector. Table 2 provides an example of the changes in yield resulting from climate change and changes in land allocation. These changes are small when compared to the calculated yield increase by technology. However, a $2 \%$ difference may directly translate in land abandonment on $2 \%$ of the agricultural area, which is a considerable area at the scale of Europe. Expansion of agriculture has a negative impact on average yield levels in most developing countries due to expansion of cropland in marginal areas while land abandonment on marginal areas in Europe leads to increases in average yield levels.

These modifications to the yield will affect production levels. Therefore, they are fed back to the GTAP model, which simulates new production results based on the adapted yields. The simulations of both models are continued iteratively until the output of the global economy and integrated assessment model with respect to agricultural land area change are consistent (Fig. 2). This way the economical and environmental processes leading to changes in agricultural area are modeled consistently and, at the same time, some global level environmental indicators can be calculated (Eickhout et al. 2007). 


\subsubsection{National-to-landscape scale models}

A spatially explicit land use change model is used to translate the aggregate land use change at the national level to high-resolution patterns $(1 \times 1 \mathrm{~km})$ of land use change for the 25 countries of the European Union. In this study the Conversion of Land Use and its Effects model (CLUE-s version 2.4; Verburg et al. 2002; Verburg and Veldkamp 2004 ) is used. The CLUE-s model is based on the dynamic simulation of competition between land uses while the spatial allocation rules can be specified based on either an empirical analysis, user-specified decision rules, neighborhood characteristics (similar to cellular automata models, Verburg et al. 2004c) or a combination of these methods. The actual allocation is based on a set of constraints and preferences that reflect the characteristics of the land use type, location and the assumed processes and constraints relevant to the scenario. Differences between scenarios are obtained by differences in data inputs and parameter settings that affect the behavior of the model. The approach considers eight different land use types: dryland arable agriculture, irrigated agriculture, grassland, abandoned agricultural land, built-up area, natural vegetation types including production forest, inland wetlands and a class of miscellaneous land use types which are assumed to show little dynamics in time (including beaches, glaciers and bare rock).

The land requirements for the different land use types determine the actual area that is allocated by the model (Fig. 2). These demands are specified for each country separately. Changes in agricultural land areas are based on the results of the combined simulations with the global economic (GTAP) and integrated assessment model (IMAGE) as described above. Growth in built-up area is calculated proportional to changes in population, GDP (as a proxy for changes in household structure and space requirements for residential and recreational purposes) and the growth in the industrial/services sectors calculated by the GTAP model. Changes in natural area are restricted by the scenario specific protection of nature reserves and, otherwise, follow land availability after accounting for changes in agricultural and built-up area. If land is available, nature development can occur spontaneous as result of re-growth of natural vegetation on abandoned lands or more directly through active management of former agricultural areas to develop natural vegetation.

Whereas the demand for land by the different land use types determines the overall competitive capacity of the different land use types, the location suitability is a major determinant of the competitive capacity of the different land use types at a specific location. It is well known that a wide range of local and regional factors can influence the suitability of a location for a land use type (Bürgi et al. 2004). Besides the commonly considered biophysical suitability in terms of crop growth potential, other factors, such as accessibility or neighborhood characteristics, should be considered as factors influencing the location suitability as perceived by the decision maker. The location suitability is a weighted average of the suitability based on empirical analysis capturing the historic and current location preferences in response to location characteristics, the influence of neighboring land uses on location suitability (e.g., in case of agglomeration effects) and suitabilities based on scenario specific decision rules. It is assumed that in the different scenarios the decision makers may have a different perception of location suitability as result of changes in worldview, policy incentives 
and extension. As an example, in the Global Economy (A1) scenario it is assumed that potential crop productivity may be a more important factor determining location suitability than in other scenarios. Empirical analysis is used to capture the current and historic preferences for locations based on a logistic regression relating land use patterns to a wide range of potential factors that are expected to determine the location suitability (Verburg et al. 2004b). The location characteristics included in this analysis include, among others, accessibility, soil and geomorphology, climate, population density and altitude. For each country the analysis was conducted separately to allow region dependent factors to be included. The empirical relations capture the current structure of land use and the response to changes in dynamic location factors (such as population), but do not allow for changes in spatial behavior as assumed in the different scenarios or the impacts of region specific policies. The latter is accounted for by the specification of area-specific conditions while changes in behavior are dealt with by adapting the calculated suitability with decision rules that reflect the assumed changes in location preferences. These include the different preferences for new built-up areas and urbanization policies.

In addition to the land requirements and location suitabilities the model accounts for land use type specific characteristics that influence the conversion and cause differences in spatio-temporal behavior. While urban growth in almost all cases results in a one-way conversion of other land uses into built-up area, arable area can still increase in part of the region while the region as a whole faces a decrease. Therefore each land use type is characterized in the model by a conversion elasticity and a specification of all plausible conversions.

Finally, for each of the scenarios, several region specific spatial policies were defined and implemented in the model. Some of these policies are implemented as a restriction on all conversions in the specified area (e.g., nature reserves) or as a restriction on specific conversions. Other spatial policies are implemented as an increase in the location suitability for one or more of the land use types in the specific area; e.g., compensation of farmers in less favored areas is implemented as an increase in location suitability relative to similar locations outside the less favored areas.

\section{Results}

\subsection{Global and European changes in land use}

Figure 4 presents the change in agricultural area in different world regions for the different scenarios based on the GTAP and IMAGE models. It is clear that Africa will experience a major increase in agricultural land in each scenario, being a result of the expected population increase in Africa in the coming 30 years. Moreover, changes in diet towards more meat also contribute to a further increase of land for grass to feed the animals. In the Global Economy (A1) scenario the increase of agricultural land is largest in most developing regions, leading to a very vulnerable situation. Further, Latin America shows a large difference between the globalized scenarios [Global Economy (A1) and Global Co-operation (B1)] and regionalized scenarios [Continental Markets (A2) and Regional Communities (B2)]. This result indicates that this region is highly 


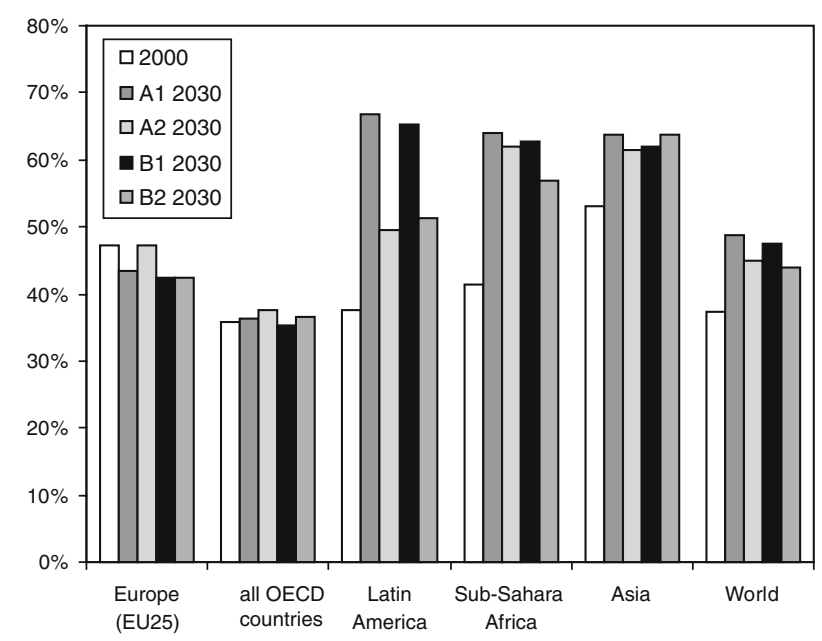

Fig. 4 Percentage of total land area occupied by agricultural use (permanent pasture and arable crops) in 2000 and 2030 for four scenarios

dependent on decisions being made for liberalization of the global agricultural market. High growth in Asia is not expected since most countries have already experienced drastic increases of agricultural land over the past 30 years (mainly China and India), leading to a high use of productive land and consequently, vulnerable situations.

In the European Union countries the growth in crop production is relatively low compared to the other world regions. Lower economic growth in combination with low income elasticity of demand is important in this respect. In spite of the small increase in crop production in the European Union the agricultural area decreases in most scenarios due to increases in crop productivity. Only the Continental Markets (A2) scenario shows a slight increase in arable land because of the high production growth as result of high economic growth, unchanged Common Agricultural Policies, an increase in high caloric food demand and protection of the Transatlantic market keeping cheaper imports outside. Moreover, land productivity increase is moderate due to segmented markets which are assumed to temper technological progress. In all scenarios more land is needed for livestock in the EU-15, which means that the land moves from crop to pasture for livestock production. In the regulated scenarios (B1 and B2) the area for livestock increases in spite of low or negative production growth. Extensification, partly because of environmental concerns, offset land abandonment.

For most scenarios the countries that joined the European Union in 2005 (EU-10) an increase in the size of the arable land until 2010 is calculated. This is caused by the benefits from the Common Agricultural Policies support measures for farmers during the first decade. The increased production will lead to an expansion of arable land in the first 10 years, after which CAP reform in the Global Economy (A1) and Global Cooperation (B1) scenarios will force these countries to intensify their agricultural practices and consequently, the size of arable land decreases again. However, this decrease is fairly small compared to the decrease in the other European countries (EU-15). 


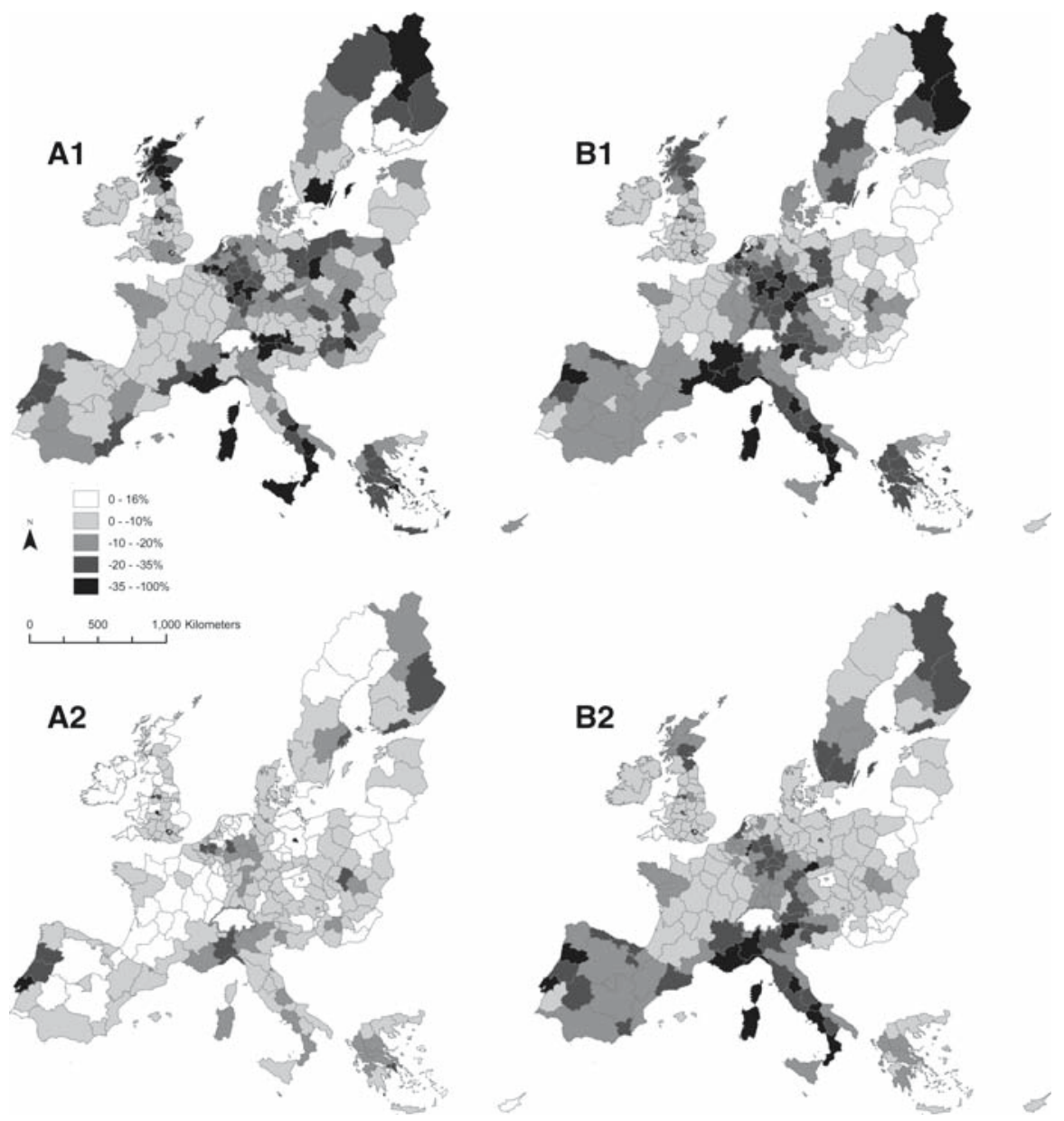

Fig. 5 Land abandonment over the period 2000-2030 expressed as the fraction of previous agricultural land (arable and grassland) converted to other uses or abandoned

Figure 5 shows the spatial distribution of land abandonment during the simulation period expressed as the fraction of the current agricultural area (grassland and arable land). Land abandonment includes here all agricultural land that is abandoned or converted to other uses. These results are aggregated by administrative region (NUTS2 level) based on the $1 \mathrm{~km}^{2}$ resolution results of the CLUE-s model. The spatial pattern is clearly different between the scenarios as result of different rates of land abandonment, spatial policies, claims for competing land uses and different preferences of decision makers. However, the scenarios have in common that most decreases in the area of agricultural land take place in either the marginal, mountainous areas or in the densely populated regions where demand of land for urban and industrial/commercial purposes is very high. The maps show that spatial variation in agricultural land abandonment is likely to be very high, some regions may lose up to two-third of the current 
agricultural area while in other areas abandonment will be negligible or include a shift from arable land to grassland. Although it is assumed that support for farming in less favoured areas will be continued in the Continental Market (A2) and Regional Communities (B2) scenarios there will still be significant land abandonment in these areas, although less severe compared to a situation where the less-favoured-area supports are abolished.

\subsection{Landscape level changes}

The results of the high-resolution pixel based land use simulations enable the analysis of changes in landscapes in more detail. These results show that the impacts on landscapes are variable across Europe and may even show opposite trends. Figure 6 shows the resulting changes in land use pattern for two different parts of Europe for the same scenario (Regional Communities B2). Strong land abandonment is observed in Northern Portugal during the first decade of the simulation (2000-2010). Only some of the flat and most fertile valleys remain in production. The lack of alternative uses in combination with depopulation of the area leads to regrowth of (semi-)natural vegetation which dominates the land use pattern in 2030. In the Baltic countries an opposite development takes place during the same period. Agriculture in these countries benefits from the Common Agricultural Policies and land intensification only takes place gradually. Increase in production is achieved by expanding the arable area at the cost

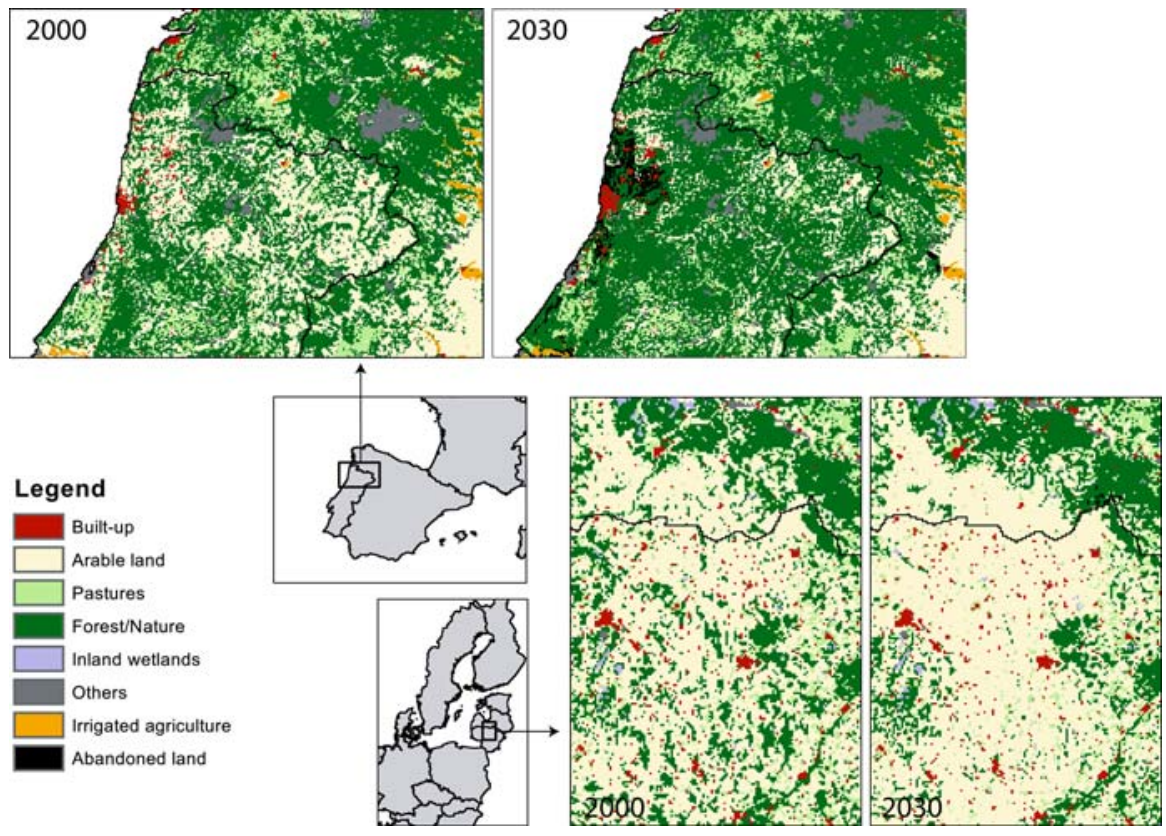

Fig. 6 Land use in the Northern region of Portugal and in the Baltic countries in the Regional Communities (B2) scenario for 2000 and 2030 

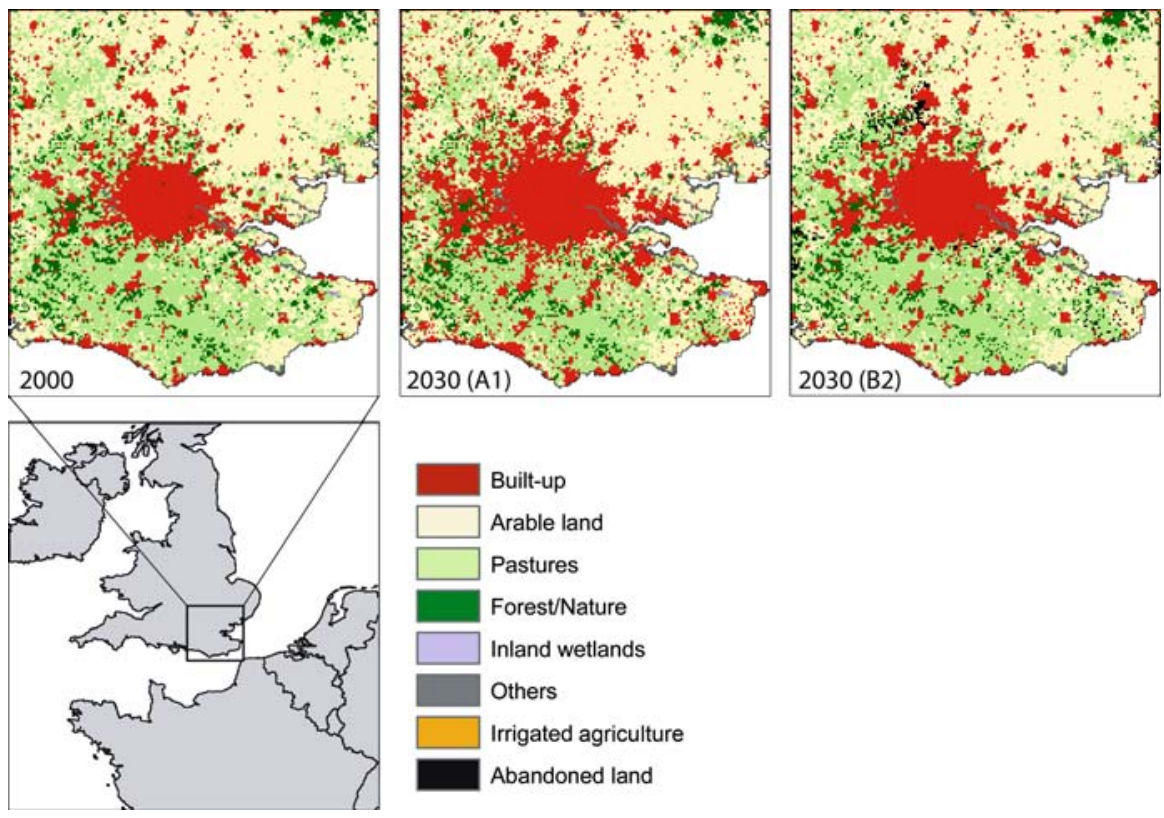

Fig. 7 Land use in South-East England for 2000 and 2030 in the Global Economy (A1) and Regional Communities (B2) scenarios

of small patches of natural vegetation, landscape elements or extensively managed areas. Although the benefits of joining the European Union decrease after 2010 there is only a limited decline in agricultural area in this region. The changes ultimately lead to a less diverse agricultural landscape while the original landscape cannot easily be restored.

In contrast to the previous example where changes in the agricultural and natural land covers dominate, Figure 7 shows the importance of urbanization for landscape change in the SouthEastern part of England including London. The results show that urbanization is very high in the Global Economy (A1) scenario whereas urban growth is much more moderate in the Regional Communities (B2) scenario, mostly due to the relatively low growth rates of population, GDP and the industrial and services sectors as compared to the Global Economy (A1) scenario. Due to the large claims on land resources by urban development and the modest decreases in agricultural area in this region in the Global Economy (A1) scenario, no abandoned farmland is observed apart from the lands that are taken over by urban purposes. In contrast, in the Regional Communities (B2) scenario some abandoned farmlands are found spread over the region.

\section{Discussion}

The methodology presented in this paper is innovative in land use modelling research since it is capable to link driving factors and land use change processes over a wide 
range of scales. Whereas in many local to regional scale land use change studies the impacts of global and continental scale changes and policies has been considered exogenous to the analysis, we have explicitly addressed the processes at these scales. This is essential when a study aims at supporting discussions among policy makers. For the support of policy discussions at the global level use is often made of global models that either focus on the economy or environmental consequences (Rosegrant et al. 2002; MEA 2005). In this study, a novel approach was taken that accounts for the interactions between economic and environmental change. In addition, a downscaling of the results to assess landscape level impacts was made. This is an essential addition. Although the regional or national aggregate change may be an important measure of the consequences of certain developments, it does not provide insight in the impact of the changes for the landscape itself. This study has indicated that changes in land use are not evenly spread over a country or region but show distinct spatial patterns. Although the aggregate decrease in agriculture for a country may be very modest, some regions within the country may still face a considerable decrease of agricultural area with large impacts on landscape, livelihood and environment. The visualisation of land use change patterns is also helpful in discussing the options of alternative policies or design targeted measures aimed at critical regions or processes of change. At the same time it is often not possible to assess the impacts on many ecological and environmental processes based on coarse resolution assessments. To make an adequate assessment of land use change effects on biodiversity, information on the spatial configuration of land use change is essential as biodiversity is not only determined by the area covered by different land use types but also by the level of fragmentation, diversity, disturbance and connectivity between areas with high biodiversity values (Wimberly and Ohmann 2004). The high resolution of the results in this study make an assessment of the effects of the different scenarios on biodiversity possible as reported by Reidsma et al. (2006) for agricultural biodiversity and Verboom et al. (2007) for biodiversity in natural land cover. Also the calculation of other indicators benefits from the high spatial resolution of the land use change assessment, e.g., the change in carbon sequestration and greenhouse gas emissions depends on the actual trajectory of land use change and location. Effects of land use change on soil erosion are negligible in areas not sensitive to erosion but may have large effects if these changes take place in an erosion-vulnerable landscape (Kosmas et al. 2000; Pardini et al. 2004). These, and other, indicators of environmental impact were calculated based on the results of the high-resolution land use model (Klijn et al. 2005). Socio-economic indicators were calculated based on the global economy model and were, inherently, only valid at the country level within the European Union countries and for larger world regions outside Europe. This coarse spatial resolution evidently has limitations but the global coverage provides the possibility to compare impacts on livelihood between Europe and regions outside Europe, esp. the developing countries, and allows the analysis of the global trade-offs of agricultural liberalization and market protection policies (Meijl et al. 2006).

The wide range of scales covered by the EURURALIS methodology for land use change analysis is unique when compared to other studies addressing European and global land use change (UNEP 2002; EEA 2005; Rounsevell et al. 2005). However, the linkage of different models over a wide range of scales inherently involves uncertainties 
and potential for error propagation. The different models traditionally use different sources of land use data, e.g., the global economy model uses agricultural statistics at country level as base data for the simulations. The land use models rely on available land use maps, in this case the European high-resolution land use inventory CORINE (CEC 1994) based on remote sensing information. These different data sources are often inconsistent and careful conversions had to be made. Furthermore, many data are collected by national agencies and may show differences in classification systems and collection methods. To minimize such errors, use has been made of datasets that are either consistently collected for the European territory or that have been harmonized from national sources (Verburg et al. 2006). Another source of uncertainty is the treatment of feedbacks between the different scales. In the global scale assessment feedbacks between economic demand and changes in productivity resulting from land use and climate change are addressed. This captures some important mechanisms that connect the economy and land use change, e.g., as a consequence of increasing demand for agricultural land less productive areas may be taken into production. This leads to a lowering of the average productivities used in the economic calculations, possibly resulting in even higher demands for agricultural area to fulfil the demand for agricultural commodities. This feedback mechanism is implemented at the global level and based on land allocation at a spatial resolution of $0.5 \times 0.5^{\circ}$. The more detailed land use allocation within Europe as made with the CLUE-s model is not accounted for. Including feedbacks between the CLUE-s model and the global models is not possible since the high-resolution simulations are only made for the European territory. Besides this mechanism it is likely that other feedbacks occur in reality, e.g., in regions with strong land abandonment the land rent may be well below the level calculated for the country as a whole, leading to the adoption of alternative land uses not considered in the country level aggregated analysis. The identification, quantification and implementation of such feedbacks is challenging since not much is known about the mechanisms and importance of such feedbacks. Fortunately this issue is high on the research agenda of the new international Global Land Project (GLP 2005).

Besides the linkage between the models that was established in this study it was also needed to make several modifications to the models themselves. One of the major achievements was the inclusion of a land supply curve within the GTAP model to capture some aspects of the land market response to land use change which is essential to link economic models to geographic approaches (Heisterman et al. 2006). Some tests have indicated that simulated agricultural land areas are very sensitive to the specification of this function. Therefore, the specification and determination of the functional form of this land suppy curve deserve more attention and possibly validation with observed changes in land value.

The validity of model results is an issue not addressed in this paper. In this respect it should be noted that the simulation results are not meant as predictions of future land use but as projections based on the assumed scenario conditions, or rather, as a quantified, visualization of the qualitative scenario descriptions. However, validation could still contribute to an assessment of the validity and uncertainty in the modeling procedure. Although different versions of the CLUE model have been validated with good results in different applications (Kok et al. 2001; Verburg et al. 2002; Pontius et al. 2006), the validity of a model is mainly determined by the case study specific 
characteristics and the quality of the input data. Therefore, a proper validation of the model simulations in this study can only be based on European land use data. This requires consistent land cover databases for 2 years which are hardly available for the European extent. The new CORINE database that highlights changes in land cover between 1990 and 2000 of the European Environmental Agency will make such a validation possible.

The methodology and land use assessment presented in this paper is able to provide information to fuel discussions on future land use, agricultural policies and spatial planning with a broad perspective on potential future developments. The four scenarios represent a wide range of developments. It is unlikely that the pathway of one of these scenarios will be followed exactly, but the four different scenarios describe a considerable part of the uncertainty in future land use trajectories and enable policy makers to focus on critical issues. Comparing the results of the different scenarios enables the identification of problems that are robust under a range of possible futures and those that are the direct consequence of specific policies or other developments assumed in one or more of the scenarios.

The application of the approach presented in this paper has been used during a presentation for the European Commission (DG Agri, May 2005) and a conference for European Union directors of Rural Affairs (November 2004). Although the method is applied in the European context, it is possible to use the same approach for other continents and countries where it is important to consider the interactions between regional development and the global economy and environment. Given the need to better connect scientific method and knowledge to policy discussions this type of approach has a high potential for improving the interaction between scientists and policy makers.

Acknowledgments This study has been conducted as part of the EURURALIS project commissioned by the Dutch Ministry of Agriculture, Nature and Food Quality. We would like to thank the whole project team for their contribution to this research. Two anonymous referees are acknowledged for their constructive comments.

\section{References}

Alcamo J, Leemans R, Kreileman E (1998) Global change scenarios of the 21st century. Results from the IMAGE 2.1 Model. Elsevier, London

Arnell NW, Livermore MJL, Kovats S, Levy PE, Nicholls R, Parry ML, Gaffin SR (2004) Climate and socio-economic scenarios for global-scale climate change impacts assessments: characterising the SRES storylines. Glob Environ Change 14:3-20

Bennett EM, Carpenter SR, Zurek M, Pingali P, Peterson GD, Cumming GC (2003) Why global scenarios need ecology. Front Ecol 1:322-329

Bollen JC, Manders T, Mulder M (2004) Four futures for energy markets and climate change. CPB Special Publication 52, ISBN 90-5833-171-7, Netherlands Bureau for Economic Policy Analysis, The Hague, and National Institute for Public Health and the Environment, Bilthoven, the Netherlands. See: http://www.mnp.nl/en

Britz W, Wieck C, Perez I, Jansson T (2002) Impact analysis of the European Commission's propsal under the Mid-Term Review of the Common Agricultural Policy (using the CAPRI model), Final report (22.08.02 AGR 019924). University of Bonn, EuroCARE, Department for Economics and Agricultural Policy, Bonn

Bürgi M, Hersperger AM, Schneeberger N (2004) Driving forces of landscape change—current and new directions. Landsc Ecol 19:857-868 
CEC (1994) CORINE land cover. Technical guide. Office for Official Publications of the European Communities, Luxembourg

Dockerty T, Lovett A, Appleton K, Bone A, Sünnenberg G (2006) Developing scenarios and visualisations to illustrate potential policy and climatic influences on future agricultural landscapes. Agric Ecosyst Environ 114:103-120

EEA (2005) http://dataservice.eea.eu.int; European Environmental Agency. In. cited on 20/08/2005

Eickhout B, van Meijl H, Tabeau A, van Rheenen T (2007) Economic and ecological consequences of four European land-use scenarios. Land Use Policy 24:562-575

Francois J, van Meijl H, van Tongeren F (2005) Trade liberalisation in the DOHA Development Round. Econ Policy 20:351-391

GLP (2005) Science Plan and Implementation Strategy Global Land Project. IGBP Report No. 53/IHDP Report No. 19. IGBP Secretariat, Stockholm

Heisterman M, Müller C, Ronneberger K (2006) Land in sight? Achievements, deficits and potentials of continental to global scale land-use modeling. Agric Ecosyst Environ 114:141-158

Hertel TW (1997) Global trade analysis: modelling and applications. Cambridge University Press, Cambridge

Huang H, van Tongeren F, Dewbre F, van Meijl H (2004) A new representation of agricultural production technology in GTAP. Paper presented at the seventh annual conference on global economic analysis, June, Washington, USA

IPCC (2000) Special report on emissions scenarios - a special report of working group III of the Intergovernmental Panel on Climate Change. Cambridge University Press, Cambridge

Klijn JA (2004) Driving forces behind landscape transformation in Europe, from a conceptual approach to policy options. In: Jongman RGH (eds) Proceedings of the Frontis workshop on the future of the European cultural landscape. Wageningen, The Netherlands 9-12 June 2002. Alterra, Wageningen

Klijn JA, Vullings LAE, van de Berg M, van Meijl H, van Lammeren R, van Rheenen T, Veldkamp A, Verburg PH, Westhoek H, Eickhout B (2005) The EURURALIS study: technical document. Alterrarapport 1196. Alterra, Wageningen

Kok K, Farrow A, Veldkamp A, Verburg PH (2001) A method and application of multi-scale validation in spatial land use models. Agric Ecosyst Environ 85:223-238

Kosmas C, Gerontidis S, Marathianou M (2000) The effect of land use change on soils and vegetation over various lithological formations on Lesvos (Greece). CATENA 40:68

Leemans R, Eickhout B (2004) Another reason for concern: regional and global impacts on ecosystems for different levels of climate change. Glob Environ Change Part A 14:219-228

Lindh T (2003) Demography as a forecasting tool. Futures 35:37-48

Loonen W, Heuberger PSC, Bakema AH, Schot P (2006) Application of a genetic algorithm to minimize agricultural nitrogen deposition in nature reserves. Agric Syst 88:360-375

MEA (2005) Ecosystems and human well-being: synthesis. Millenium Ecosystem Assesment. Island Press, Washington

Meijl Hv, Tongeren FWv (2002) The Agenda 2000 CAP reform, world prices and GATT_WTO export constraints. Eur Rev Agric Econ 29:445-470

Meijl Hv, van Rheenen T, Tabeau A, Eickhout B (2006) The impact of different policy environments on agricultural land use in Europe. Agric Ecosyst Environ 114:21-38

Nassauer JI (1995) Culture and changing landscape structure. Landsc Ecol 10(4):229-237

Naveh Z (2001) Ten major premises for a holistic conception of multifunctional landscapes. Landsc Urban Plan 57(3-4):269-284

OECD (2003) Agricultural Policies in OECD Countries 2000. Monitoring and evaluation. Organization for Economic Co-operation and Development, Paris

Pardini G, Gispert M, Dunjo G (2004) Relative influence of wildfire on soil properties and erosion processes in different Mediterranean environments in NE Spain. Sci Total Environ 237-328, 246

Parry ML, Rosenzweig C, Iglesias A, Livermore M, Fischer G (2004) Effects of climate change on global food production under SRES emissions and socio-economic scenarios. Glob Environ Change 14:5367

Peterson GD, Beard TD, Beisner BE, Bennett EM, Carpenter SR, Cumming GC, Dent CL, Havlicek TD (2003) Assessing future ecosystem services: a case study of the Northern Highland Lake District, Wisconsin. Conserv Ecol http://www.ecologyandsociety.org/vol7/iss3/art1/index.html

Pontius RG, Boersma W, Castella J-C, Clarke K, Nijs Td., Dietzel C, Duan Z, Fotsing E, Goldstein N, Kok K, Koomen E, Lippitt CD, McConnell W, Pijanowski B, Pithadia S, Sood AM, Sweeney S, Trung 
TN, Veldkamp A, Verburg PH (2006) Comparing the input, output, and validation maps for several models of land change. Ann Region Sci (this issue)

Rabbinge R, van Diepen CA, Dijsselbloem L, Koning GHJ, van Latesteijn HC, Woltjer E, van Zij1 J (1994) Ground for choices: a scenario study on perspectives for rural areas in the European Community. In: Fresco LO, Stroosnijder L, Bouma J, van Keulen H (eds) The future of the land: mobilising and integrating knowledge for land use options. Wiley, New York, pp 95-121

Reidsma P, Tekelenburg T, van den Berg M, Alkemade R (2006) Impacts of land use change on biodiversity: an assessment of agricultural biodiversity in the European Union. Agric Ecosyst Environ 114:86-102

Rosegrant MW, Meijer S, Cline SA (2002) International model for policy analysis of agricultural commodities and trade (IMPACT): model description. International Food Policy Research Institute, Washington, p 28

Rotmans J, Asselt MA, Anastasi C, Greeuw S, Mellors J, Peters S, Rothman D, Rijkens N (2000) Visions for a sustainable Europe. Futures 32:809-831

Rounsevell MDA, Ewert F, Reginster I, Leemans R, Carter TR (2005) Future scenarios of European agricultural land use: II. Projecting changes in cropland and grassland. Agric Ecosyst Environ 107:101-116

Schröter D, Cramer W, Leemans R, Prentice CI, Araujo MB, Arnell NW, Bondeau A, Bugmann H, Carter TR, Gracia CA, de la Vega-Leinert AC, Erhard M, Ewert F, Glendining M, House JI, Kankaanpaa S, Klein RJT, Lavorel S, Lindner M, Metzger MJ, Meyer J, Mitchell TD, Reginster I, Rounsevell M, Sabate S, Sitch S, Smith B, Smith J, Smith P, Sykes MT, Thonicke K, Thuiller W, Tuck G, Zaehle S, Zierl B (2005) Ecosystem service supply and vulnerability to global change in Europe. Science 310:1333-1337

Strengers B, Leemans R, Eickhout B, De Vries B, Bouwman AF (2004) The land-use projections and resulting emissions in the IPCC SRES scenarios as simulated by the IMAGE 2.2 model. GeoJ 61:381-393

UNEP (2002) Global Environment Outlook 3. UNEP, Nairobi

van Ittersum MK, Roetter RP, van Keulen H, de Ridder N, Hoanh CT, Laborte AG, Aggarwal PK, Ismail AB, Tawang A (2004) A systems network (SysNet) approach for interactively evaluating strategic land use options at sub-national scale in South and South-east Asia. Land Use Policy 21:101-113

Verboom J, Alkemade R, Klijn JA, Metzger MJ, Reijnen R (2007) Combining biodiversity modeling with political and economic development scenarios for 25 EU countries. Ecolo Econ 62:267-276

Verburg PH, Veldkamp A (2004) Projecting land use transitions at forest fringes in the Philippines at two spatial scales. Landsc Ecol 19:77-98

Verburg PH, Soepboer W, Limpiada R, Espaldon MVO, Sharifa M, Veldkamp A (2002) Land use change modelling at the regional scale: the CLUE-S model. Environ Manage 30:391-405

Verburg PH, Ritsema van Eck J, de Nijs T, Dijst MJ, Schot P (2004) Determinants of land use change patterns in the Netherlands. Environ Plann B 31:125-150

Verburg PH, Schulp CJE, Witte N, Veldkamp A (2006) Downscaling of land use change scenarios to assess the dynamics of European landscapes. Agric Ecosyst Environ 114:39-56

Wester-Herber M (2004) Underlying concerns in land-use conflicts-the role of place-identity in risk perception. Environ Sci Policy 7:109

Westhoek HJ, van den Berg M, Bakkes JA (2006) Scenario development to explore the future of Europe's rural areas. Agric Ecosyst Environ 114:7-20

Wimberly MC, Ohmann JL (2004) A multi-scale assessment of human and environmental constraints on forest land cover change on the Oregon (USA) coast range. Landsc Ecol 19:631-646

WRR (1992) Ground for choices: four perspectives for the rural areas in the European Community. SDU Uitgevers, The Hague

Xiang W-N, Clarke KC (2003) The use of scenarios in land-use planning. Environ Plann B 30:885-909 